\title{
Variation of PEFR with Height, Weight and Waist-Hip Ratio in Medical Students
}

\begin{abstract}
Hasnain Abbas Dharamshi ${ }^{1}$, Ahmad Faraz ${ }^{1}$, Erum Ashraf ${ }^{2}$, Syed Sajjad Alam ${ }^{3}$, Amar Ali ${ }^{4}$, Osama Shakeel ${ }^{1}$, Syed Muhammad Ali Abidi ${ }^{5}$, Shahraiz Shah Rizvi ${ }^{1}$, Zehra Fatima ${ }^{5}$, Hafiz Abdul Wasy ${ }^{1}$, Farwa Fatima ${ }^{6}$, Marvi Mahar ${ }^{2}$, Tahira Naqvi ${ }^{1}$
\end{abstract}

\section{Abstract}

Objective: The primary aim of our study was to assess the variation of PEFR with various anthropometric measurements in medical students of Karachi, Pakistan.

Design: Cross-sectional study.

Setting: Medical students of Karachi Medical and Dental College.

Participants: 276 non-smoker healthy medical students composed of 168 females and 108 males.

Variable parameters: They include mean age, body height and body weight and PEFR. They were marked separately for each gender.

Results: The mean waist hip ratio in females was observed to be $0.843 \pm 0.111$ in relation with that of mean PEFR value $452.97 \pm 65.84$ $\mathrm{L} / \mathrm{min}$, whereas in males the mean waist hip ratio was $0.864 \pm 0.028$ in relation with that of mean PEFR value $445.93 \pm 66.49 \mathrm{~L} / \mathrm{min}$. Also there is a statistically significant variation in PEFR with an increase in waist hip ratio. The mean height of males was $173.63 \pm 7.5 \mathrm{~cm}$ and weight was $61.81 \pm 11.25 \mathrm{Kg}$ while mean height of females was $158.56 \pm 7.3$ $\mathrm{cm}$ and weight was $49.33 \pm 9.04 \mathrm{Kg}$. PEFR is positively correlated with increase in height and weight up to a certain limit.

Conclusion: The study concludes that PEFR is affected positively by variation in waist hip ratio; moreover young females have more
1 Karachi Medical and Dental College.

2 Jinnah Medical and Dental College.

3 Bahria University Medical and Dental College.

4 Hamdard University of Pharmacy.

5 Sindh Medical College.

6 Dow Medical College.

Contact information:

Hasnain Abbas Dharamshi.

”d dr.hasnain.dh@hotmail.com 
waist hip ratio and PEFR values than their young male counterparts. A large sample size with accurate peak flow meter is required along with ethnic consideration of the study population for better, accurate and clear results.

\section{Keywords}

Height; weight; Pefr; waist; hip. Pefr: Peak expiratory flow rate. WHR: Waist hip ratio

\section{Introduction}

PEFR measurement is a simple test of respiratory function used in the diagnosis and prognosis of obstructive airway disease including bronchial asthma. It can be easily measured and correlates well with other lung function measurements. However, for the meaningful interpretation of PEFR results, it is necessary to establish the normal range of observations specific to a population, since there are wide variations of PEFR with geographic, racial, genetic and nutritional background [1, 2, 3] It is defined as "The largest expiratory flow rate achieved with a maximally forced effort from a position of maximal inspiration, expressed in liters/min" [4] Besides fulfilling the need of assessing the ventilatory function peak flow meter is a reliable and safe instrument. It is suitable for studies of respiratory function due to its portability and simplicity $[5,6]$. Peak Expiratory Flow Rate (PEFR) can be assessed by using Peak Flow Meters that are relatively inexpensive but are of value in identifying and assessing the degree of air flow limitations of individuals. [7] Measurement of peak expiratory flow rate (PEFR) or FEV provides objective evidence of the extent of air-way obstruction, and is often a more reliable indicator of the severity of an acute asthma attack than the patient's history or findings on physical examination. [8]Serial measurement of FEV or PEFR can be used to assess response to treatment. Peak expiratory flow rate and to a lesser extent, FEV are, however, effort-dependent tests, especially in an acute setting. [9] Pulse oximetry and/or arterial blood gas determination are helpful in assessing the degree of respiratory insufficiency. Many reports have been published on the variations of various ventilatory parameters with anthropometric determinants like height and weight in former studies. Recently various scientific studies have been carried out to relate PEFR to height and weight of the subjects. [10, 11, 12, 13] Conflicting reports have also been documented [14]. The present study has been taken up to look into the relationship between PEFR and anthropometric parameters such as height and weight in males and females and determining which factor has a stronger association with PEFR. Pulmonary studies carried out in western world significantly vary with those carried out in the Asian subcontinent, the reason being significant differences in anthropometric parameters. Respiratory pressures significantly vary in different ethnic groups and sub groups. Related results have been reported in Malaysian populations which consist of three main ethnic groups, namely Malays, Chinese and Indians.15 There are various factors by which PEFR values are affected, such as body surface area, posture, obesity, physical activity, sex, racial and environment differences.[16, 17, 18] Obesity has been connected with impaired airway hyper responsiveness and pulmonary function, [19, 20] but not in all studies and with asthma in adults. $[21,22]$ In a lean person, the waist can be measured at its narrowest point, while for a person with convex waist; it may be measured at about one inch [23]. The aim of the present study is" To determine the pulmonary function parameters in normal young healthy non- smoking male and female medical students of Karachi Medical and Dental College in order to get normal reference values for population of 
Karachi". An attempt has been made through this present study to assess pulmonary functions among the medical students as pulmonary function tests (PFT) are one of the indicators of the health status of the individuals.

\section{Methodology}

This cross-sectional study was conducted in Karachi Medical and Dental College from March 2014 to September 2014. A total of 276 non-smoking healthy young Pakistani subjects were randomly selected. The study population belonged to the age group of 18-25 year. The mean age, body height, weight and waist hip ratio was recorded and calculated in male and female groups, respectively. Students having exercise, or existing respiratory diseases and taking treatment for any respiratory disease are excluded from the study. The experimental protocol like breathe in as deeply as they can, blow into the mouth pieces with nostrils closed as quickly and as hard as they can, don't put tongue in front of the mouthpiece, do these for three times, and if they cough or sneeze while breathing out, they will need to start again. All were explained to all the volunteers individually. The subjects were advised to avoid wearing any tight clothes.

During the same time of the day the subjects were comfortably seated and were asked to relax physically and mentally then the vitals like blood pressure pulse respiratory rates were taken then PEFR were measured with standing height measured in centimeter with standard height measuring rods and weights were measured in kilograms with calibrated Libra weighing scale It was determined in liters/minute with the help of Mini Wright Peak Flow Meter.

Each subject was made three PEFR measurement maneuvers with all protocols and the highest value considered. Similar procedure was followed for categorizing the subjects according to their weight. P-value less than or equal to 0.05 ( $p \leq 0.05$ ) is considered as statistically significant.. All statistical analysis is done using SPSS 17.

\section{Results}

Out of the total 276 undergraduate medical students enrolled in this study. Total 168 females (60.87\%) were between the mean age of 18.68 and 108 males $(39.13 \%)$ were between the mean age of 18.33 respectively. Table 1 reflects the distribution of the study population in terms of percentage.

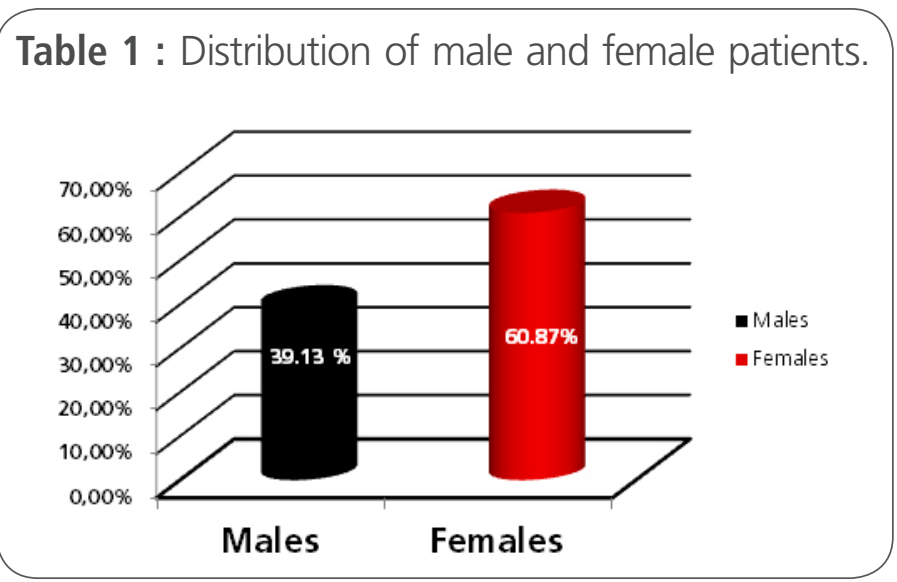

Moreover Table $\mathbf{2} \& \mathbf{3}$ shows the correlation between number of persons and their mean PEFR with their respective waist hip ratios in females and males.

Table 2. Variation of PEFR with waist hip ratio in Females.

\begin{tabular}{|c|c|c|}
\hline Waist hip ratio & No of persons & PEFR (MEAN \pm S.D) (L/min) \\
\hline $0.50-0.70$ & 74 & $457.89 \pm 64.57$ \\
\hline 0.71 .0 .90 & 54 & $444.26 \pm 63.50$ \\
\hline$>.91$ & 40 & $421.48 \pm 58.23$ \\
\hline $\begin{array}{l}\text { Correlation coef } \\
(r)=0.61 * N=16\end{array}$ & & $=$ Positive correlation \\
\hline
\end{tabular}

Table 3. Variation of PEFR with waist hip ratio in males.

\begin{tabular}{|c|c|c|}
\hline Waist hip ratio & No of persons & PEFR (MEAN \pm S.D) (L/min) \\
\hline $0.50-0.70$ & 37 & $468.52 \pm 59.63$ \\
0.71 .0 .90 & 42 & $451.83 \pm 63.65$ \\
\hline$>.91$ & 29 & $443.49 \pm 59.21$ \\
\hline $\begin{array}{l}\text { Correlation coefficient } \\
(r)=0.12 *\end{array}=108$ & $*$ * Positive correlation \\
\hline
\end{tabular}


It is further observed that the mean Waist hip ratio in males was found to be $0.864 \pm 0.028$ corresponding with that of mean PEFR value $445.93 \pm 66.49$ $\mathrm{L} / \mathrm{min}$, whereas in females the mean Waist hip ratio was $0.843 \pm 0.111$ corresponding with that of mean PEFR value $452.97 \pm 65.84 \mathrm{~L} / \mathrm{min}$.

Table 4 shows the height of normal adult male along with their corresponding mean PEFR recorded in each age group. It is cleared by looking the chart that there is increased tendency of PEFR with increasing height at certain level and then drop as the height increase to specific point i.e. $181-190 \mathrm{~cm}$.

Table 4. Variation of Height with Peak Expiratory Flow Rate in Normal Young Adult Males.

\begin{tabular}{|c|c|c|}
\hline Height $(\mathbf{c m})$ & Number of persons & PEFR $($ Mean \pm SD) $($ L/min) \\
\hline $151-160$ & 33 & $450 \pm 00.00$ \\
$161-170$ & 29 & $548.75 \pm 55.146$ \\
$171-180$ & 28 & $584.00 \pm 76.60$ \\
$181-190$ & 18 & $550 \pm 80.83$ \\
$\begin{array}{l}\text { Correlation coefficient } \\
\text { (r) }=0.294^{*}, N=108\end{array}$ & *= Positive correlation
\end{tabular}

Table 5 narrates the male medical students grouped according to their weight and the mean PEFR observed in each group. With weight also, we can see a gradual rise in PEFR to certain level of $51-60 \mathrm{~kg}$ and then drop as the weight further increases.

Table 5. Variation of Weight with Peak Expiratory Flow Rate in Normal Young Adult Males.

\begin{tabular}{|c|c|c|}
\hline Weight (Kg) & Number of persons & PEFR (MEAN \pm SD) (L/min) \\
\hline $41-50$ & 15 & $546.67 \pm 83.58$ \\
$51-60$ & 27 & $598.00 \pm 43.24$ \\
$61-70$ & 23 & $554.55 \pm 89.03$ \\
$71-80$ & 28 & $582.50 \pm 112.65$ \\
$81-90$ & 15 & $550.00 \pm 00.00$ \\
\begin{tabular}{l|l} 
Correlation coefficient \\
(r) $=0.845^{*}, N=108$
\end{tabular} & *= Positive correlation \\
\hline
\end{tabular}

Having a thorough view of Table 4 and $\mathbf{5}$, it is quite clear that a stronger association exists between PEFR and height as compared to weight of male subjects.
Table 6 shows female students grouped together according to their height and mean PEFR recordings. The table also shows PEFR increases in young adult female students to certain level of height i.e. 151$160 \mathrm{~cm}$ and then decrease as the height further increases.

Table 6. Variation of Height with Peak Expiratory Flow Rate in normal Young Adult Females.

\begin{tabular}{|c|c|c|}
\hline Height $(\mathrm{cm})$ & Number of persons & PEFR (Mean \pm SD) (L/min) \\
\hline $140-150$ & 36 & $334.37 \pm 66.93$ \\
$151-160$ & 57 & $343.78 \pm 70.46$ \\
$161-170$ & 42 & $331.67 \pm 58.38$ \\
$181-190$ & 33 & $250 \pm 00.00$ \\
\hline $\begin{array}{l}\text { Correlation coefficient } \\
(r)=0.306^{*}, N=168\end{array}$ & $*$ * Positive correlation \\
\hline
\end{tabular}

Table 7. Variation of Weight with Peak Expiratory Flow Rate in Normal Young Adult Females.

\begin{tabular}{|c|c|c|}
\hline Weight (Kg) & Number of persons & PEFR (MEAN \pm S.D) (L/min) \\
\hline $30-40$ & 29 & $340.91 \pm 66.182$ \\
$41-50$ & 55 & $334.46 \pm 61.30$ \\
$51-60$ & 41 & $336.06 \pm 64.138$ \\
$61-70$ & 20 & $340 \pm 15.81$ \\
$71-80$ & 21 & $328.00 \pm 118.19$ \\
\hline $\begin{array}{l}\text { Correlation coefficient } \\
\text { (r) =0.774* }{ }^{*} \text { N=168 }\end{array}$ & * = Positive correlation \\
\hline
\end{tabular}

The association of PEFR with height and weight in both genders male and females increases to certain level of increasing height and weight and then decreases as the height and weight increases further.

Table 8. Means of different variables.

\begin{tabular}{|l|c|c|c|} 
& $\begin{array}{c}\text { Height } \\
(\mathrm{MEAN} \pm \text { SD) } \\
(\mathbf{c m})\end{array}$ & $\begin{array}{c}\text { Weight }(\mathrm{MEAN} \pm \mathrm{SD}) \\
(\mathrm{Kg})\end{array}$ & $\begin{array}{c}\text { Waist hip Ratio } \\
(\mathrm{MEAN} \pm \text { SD) }\end{array}$ \\
\hline Males & $173.63 \pm 7.5$ & $61.81 \pm 11.25$ & $0.864 \pm 0.028$ \\
\hline Female & $158.56 \pm 7.3$ & $49.33 \pm 9.04$ & $0.843 \pm 0.111$ \\
\hline
\end{tabular}

\section{Discussion:}

The primary factors that affect PEFR are the strength of the expiratory muscles producing the contraction, the recoil pressure of the lungs and the 
airway competency. [24] Significant correlation has been previously reported for PEFR with height, weight, age, socioeconomic conditions, chest circumference and body surface area. [25] This study reflected interesting association between waist hip ratio and PEFR values with increasing tendency in the values of latter with the increase in the former values. Also it was found that $44.04 \%$ of the female participants had higher PEFR than 457.8, moreover $23.8 \%$ of females had waist hip ratio greater than 0.91 . However this relationship of PEFR was contrasted by the results given by ANURADHA R. JOSHI. [26] On the other hand the mean waist hip ratio of females was found to be $0.843 \pm 0.111$ and males were $0.864 \pm 0.028$, this shows that males had higher mean waist hip ratio as compared to females counterparts respectively. Similar finding was reported by Mungreiphy NK. [27] Consistent with other research studies, the mean WHR values were found out to be greater in male participants than the female participants. [28] The study also reported interesting relationship between height and weight with PEFR that shows PEFR values increases to certain levels of increasing weight and height and then it start decreasing as height and weight further increases. The mean values of height, weight and PEFR were higher for males than females. Similar findings were reported by J. Mishra [29]. This study also showed that in males, PEFR increases significantly with height $(r=0.294)$ and weight $(r=0.845)$, which is in agreement with the reports of certain other investigators.[30, 31, $32,33]$ A large sample by increasing size and random selection of subjects from general population instead of students of medical school is needed to get more accurate results.

\section{Conclusion}

The male's height is having better association with PEFR and female weight is having better correlation with PEFR, the study also concludes that PEFR is affected positively by variation in waist hip ratio; moreover young females have more waist hip ratio and PEFR values than their young male counterparts.

\section{References}

1. Patricia AAgaba, Tom D Thacher, Ishaya A Angyo, Emmanuel I Agaba. Peak Expiratory Flow Rate in Healthy Nigerian Children. J Trop Ped; 2003.

2. Hellmann S, Goren Al. The necessity of buildingpopulation specific prediction equations forclinical assessment of pulmonary function tests. Eur J Pediatr;1999 Jun.

3. Mridha MA, Kabir ARML, Amin MR. Peak Expiratory Flow Rate (PEFR.- A simpleventilator lung function test. A review article. [Internet] [Cited 2012 June 07].

4. American Thoracic Society: Standardization of Spirometry; 1994 update. Amer J Respir\& Critical Care Med 1995; 152: 1107-1136.

5. Pande JN, Mohan A, Khilani S, Khilani GC. Peak expiratory flow rates in school going children. Indian J Chest Dis \& Allied Sci, 1997; 39: 87-95.

6. Venkatesan EA, Walter S, Ray D. An assessment of peak flow meters on human volunteers. Indian J PhysiolPharmacol 1994; 38: 285-288

7. Benjaponpitak S, Direkwattanachai C, Kraisarin C, Sasisakulporn C. Peak expiratory flow rate values of students in Bangkok. J Med Assoc Thai 1999;82 (Suppl.): 137-43.

8. Practice parameters for the diagnoses and treatment of asthma. J AllergClinImmunol; 1995

9. http://www.hopkinsmedicine.org/healthlibrary/test_ procedures/pulmonary/peak_flow_measurement_92,P07755/

10. Azah, N., Antai, E.J., Peters, E.J., Osim, E.E. (2002). Normal lung function values of Nigerian children aged 6-16 years. Nig. J. Physiol. Sci. 17(1-2): 74-75.

11. Elebute, E.A., Femi-Pearse, D. (1971). Peak Flow rate in Nigeria: Anthropometric determinants and usefulness in assessment of ventilatory function. Thorax. 26: 597

12. Ali, M.A. (1983). Ventilatory functions in non- smoking healthy Nigerian adults. W.Afr. J. Med. 2(1): 1-8.

13. Jajaa, S.I., Ojo, G.O. (1983). Peak flow rates in young Nigerian adults. Nig. J. Physiol. Sci. 1(2): 24-30.

14. Gupta CK, Neeraj Mathur. Statistical models relating peak expiratory flow rates to age, height, and weight in men and women. Journal of Epidemiology and Community Health, 1982, $36,64-67$

15. M. I. Ebomoyi,v. I. Iyawe. Variations of peak expiratory flow rate with anthropometric determinants in a population of healthy adult nigerians. Nigerian Journal of Physiological Sciences 20 (12): 85-89@ Physiological Society of Nigeria, 2005 
16. Benjaponpitak S, Direkwattanachai C, Kraisarin C, Sasisakulporn C. Peak expiratory flow rate values of students in Bangkok. J Med Assoc Thai 1999;82 (Suppl.): 137-43.

17. Srinivas P, Chia YC, Poi PJ, Ebrahim S. Peak expiratory flow rate in elderly Malaysians. Med J Malaysia 1999;54: 11-21.

18. Raju PS, Prasad KV, Ramana YV, Murthy KJ. Pulmonary function tests in Indian girls prediction equations. Indian J Pediatr 2004;71: 893-7.

19. Gibson GJ. Obesity, respiratory function andbreathlessness. Thorax 2000; 55 (Suppl. 1): S41-S44.

20. Rubinstein I, Zamel N, DuBarry L, Hoffstein V. Airflowlimitation in morbidly obese, nonsmoking men. Ann InternMed 1990; 112: 828-32.

21. Young SY, Gunzenhauser JD, Malone KE, McTiernanA.Body mass index and asthma in the military populationof the northwestern United States. Arch Intern Med2001; 161: 1605-11.

22. Ferretti A, Giampiccolo P, Cavalli A, Milic-EmiliJ,Tantucci C. Expiratory flow limitation and orthopneainmassively obese subjects. Chest 2001; 119: 1401-8.

23. Brown, J. E.; Potter, J. D.; Jacobs, D. R.; Kopher, R. A.; Rourke, M. J.; Barosso, G. M.; Hannan, P. J.; Schmid, L. A. (1996). "Maternal Waist-to-Hip Ratio as a Predictor of Newborn Size: Results of the Diana Project". Epidemiology7 (1): 62-6.

24. Sahebjami H. Dyspnea in obese healthy men. Chest 1998; 114 : 1373-7.

25. Indian Journal of Public Health Vol.51 No.2 April - June, 20071

26. Anuradha R. Joshi*, Ratan singh and a. R. Joshi, correlation of pulmonary function tests with body fat percentage in young individuals. Indian j physiolpharmacol 2008; 52 (4.: 383-388

27. Mungreiphy NK, Dhall M, Tyagi R, Saluja K, Kumar A, Tungdim $M G$, et al. Ethnicity, obesity and health pattern among Indian population. J Nat ScBiol Med 2012; 3: 52-9.

28. D. V. Muralidhara and M. Ramesh Bhat, Some Aspects of Pulmonary Functions in the Underweight and Overweight Human Subjects, Thai Journal of Physiological Sciences.Vol. 20 No. 1 Mar.-Sept. 2007

29. J. Mishra, S. Mishra, S. Satpathy, Variations in PEFR among Males and Females With Respect To Anthropometric Parameters (IOSR-JDMS. e-ISSN: 2279-0853, p-ISSN: 2279-0861. Volume 5, Issue 1 (Mar-Apr 2013), PP 47-50

30. Azah, N., Antai, E.J., Peters, E.J., Osim,E.E. (2002). Normal lung function values of Nigerian children aged 6-16 years. Nig. J. Physiol. Sci. 17(1-2): 74-75.

31. Elebute, E.A., Femi-Pearse, D. (1971). Peak Flow rate in Nigeria: Anthropometric determinants and usefulness in assessment of ventilatory function. Thorax. 26: 597

32. Ali, M.A. (1983). Ventilatory functions in non- smoking healthy Nigerian adults. W.Afr. J. Med. 2(1): 1-8

33. Jaja, S.I., Ojo, G.O. (1983). Peak flow rate in young Nigerian adults. Nig. J. Physiol. Sci. 1(2): 24-30

\section{Comment on this article:}

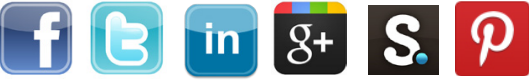

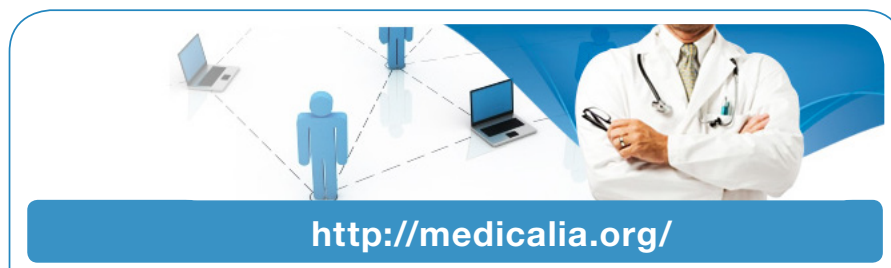

Where Doctors exchange clinical experiences, review their cases and share clinical knowledge. You can also access lots of medical publications for free. Join Now!

\section{Publish with iMedPub}

\section{http://www.imed.pub}

International Archives of Medicine is an open access journal publishing articles encompassing all aspects of medical science and clinical practice. IAM is considered a megajournal with independent sections on all areas of medicine. IAM is a really international journal with authors and board members from all around the world. The journal is widely indexed and classified Q1 in category Medicine. 